\title{
OPTIMISING THE GRINDING WHEEL DESIGN FOR FLUTE GRINDING PROCESSES UTILISING NUMERICAL ANALYSIS OF THE COMPLEX CONTACT CONDITIONS
}

\begin{abstract}
Resource efficiency is gaining relevance in every aspect of production. Hence, cutting tools are exposed to high demands regarding productivity and quality. Considering the various grinding operations in tool manufacturing, flute grinding is the most significant process step as it defines the peripheral cutting edge and the rake face. Therefore, it has a substantial influence on the machining behaviour of, for example, milling tools. When it comes to helical flutes, the complex contact conditions between grinding wheel and tool blank during the multiaxial grinding process are particularly difficult to determine. Due to the lack of knowledge about those contact conditions, the grinding wheels typically used for flute grinding cannot wholly meet the actual process requirements. In order to optimise the design of the grinding wheels, a numerical model was developed. Based on that, a simulation tool was implemented to analyse the complex contact conditions during flute grinding depending on the process parameters and tool/workpiece geometry. The influence of different grinding parameters on the effective contact length, the specific material removal rate and the equivalent chip thickness was evaluated by employing the computer-based model. The generated results were then used to develop a new optimised tool concept for a more efficient flute grinding process.
\end{abstract}

\section{INTRODUCTION}

The performance of milling tools is significantly influenced by the tool manufacturing processes. During the process chain of milling tool manufacturing, three different grinding operations are necessary: flute, circumferential and face grinding. Due to its major influence on the geometry and quality of the cutting edge, flute grinding is considered to be the most important process step. Besides its dominating influence on the cutting-edge generation, flute grinding also has the highest material removal $V_{w}$ which goes along with a high primary processing time [1,2]. To maximise productivity and increase economic efficiency, the flute is usually manufactured by creep feed grinding The grinding of helical flutes is especially challenging. The multiaxial process kinematics lead to highly complex contact conditions and

\footnotetext{
${ }^{1}$ Institute for Machine Tools and Factory Management (IWF) - TU Berlin, Germany

*E-mail: bernhard.guelzow@iwf.tu-berlin.de https://doi.org/10.36897/jme/119641
} 
non-constant loads of the grinding wheel over the active grinding wheel width $b_{\text {s.act }}$ [3-5]. To achieve a more profound understanding of the flute grinding process it is necessary to be aware of the cause-effect relationships between geometrical and kinematical parameters and grinding relevant values. Such knowledge could build the basis for new application related design concepts for grinding wheels and the optimisation of the process itself to increase the productivity and resulting milling tool quality.

One of the first scientific publications about simulating a tool grinding process was published by Friedmann et al. [6]. The first approaches to include Computer-Aided Design / Manufacturing (CAD / CAM) were presented in 1988 [7]. Nowadays CAD / CAM programs are utilised to determine the flute geometry by simulating the penetration of solid bodies [8-10] However, most of the existing models to describe the geometrical-kinematic relationships are based on analytical solutions using differential geometry [11-14]. In more recent works similar numerical approaches as presented in this paper were used to analyse influence of the grinding wheel's geometry and position on the flute's shape $[15,16]$.

Based on the work of Li et al. [17] a numerical model was implemented that depicts the processes kinematic and calculates the resulting flute cross-section according to the key parameters defining the flute's geometry. In order to study the complex contact conditions an innovative algorithm was developed that calculates the active grinding wheel surface. By analysing that surface different grinding specific parameters such as the material removal rate $Q^{\prime}{ }_{w}$ or the maximum chip thickness $h_{c h \text { max }}$ can directly be derived and evaluated over the active grinding wheel width $b_{\text {s.act. }}$

In this paper, the simulation tool and the theory behind it are being explained. Furthermore, the simulative investigations of the influence of different geometrical and kinematical parameters on the grinding specific values will be presented as well as a design concept for grinding wheels based on the conclusions.

\section{GEOMETRICAL-KINEMATIC MODEL FOR THE FLUTE GRINDING PROCESS}

The geometrical-kinematic simulation tool contains five main parts: The discretisation of the grinding wheel surface, the automatic positioning of the grinding wheel relative to the workpiece, the kinematic model of the grinding process, the determination of the active grinding wheel surface and the derivation of relevant grinding values. Starting with the description of the grinding wheel, two different profile types can be realised. As shown in Fig. 1a, the first approach considers an ideal edge with a given radius $r_{\beta S}$ as well as the wheel diameter $d_{S}$, the wheel width $b_{S}$ and the profile angle $\alpha_{S}$. With the second approach, a more complex edge shape can be described. In addition to the parameters of the first approach, the edge shape is defined by two length parameters $k_{1}$ and $k_{2}$, as illustrated in Fig. 1b. The effective profile, meaning side, edge and circumference of the grinding wheel, can then be described piecewise continuously by either approach, such that the contour can be discretised in any desired resolution. By rotating the contour around the central axis, the grinding wheels effective circumferential surface is completely described by a discrete point set. 

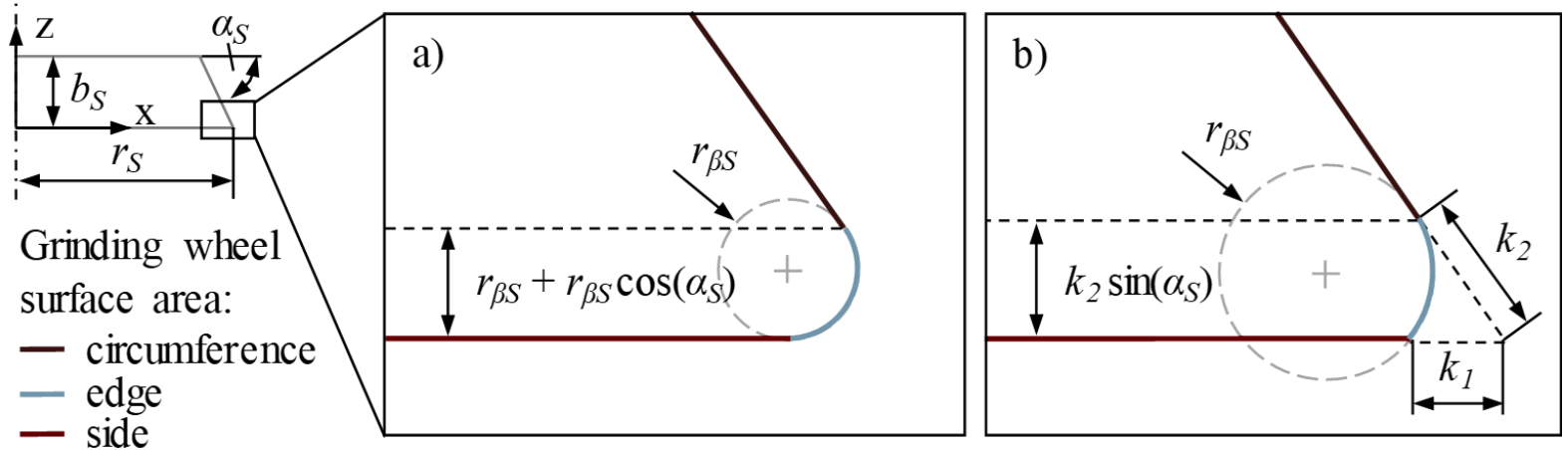

Fig. 1. Schematic representation of the analytical description of the grinding wheel contour: a) ideal edge geometry, b) complex edge geometry (k-model)

In order to move the grinding wheel to its starting position relative to the workpiece $\left\{x_{0}, y_{0}, z_{0}\right\}$ a coordinate transformation with respect to all six degrees of freedom is performed [17] Hereby the workpiece's origin is represented by the global coordinate system $\{x, y, z\}$. According to Fig. 2, the parameters $a_{0}, b_{0}$ and $c_{0}$ define the translational offset and $d_{0}, f_{0}$ and $e_{0}$ are rotating the local coordinate system around the respective axes.

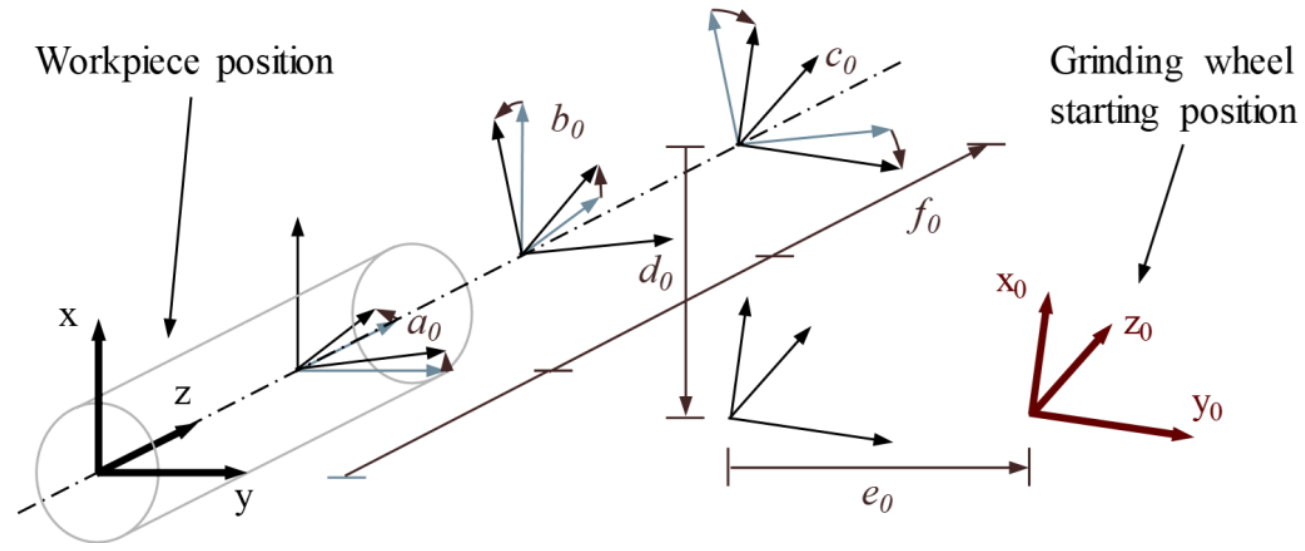

Fig. 2. Exemplary presentation of coordinate transformation to define the grinding wheel starting position

The flute grinding process kinematics can be modelled, as described by equation 1, by a combination of translational movement along and rotation around the $z$-axis. The flute's helix angle $h$ is defined by the desired geometry of the milling tool and the coordinates $\left\{x_{t}, y_{t}, z_{t}\right\}$ are giving the exact position of any discrete point of the grinding wheel surface after the wheel has rotated $t$ degrees around the workpiece blank's central axis during the grinding process.

By varying the angular coordinate $t$, a set of grinding wheel surfaces can be determined along the grinding path. The more efficient approach to determine the flute profile is to calculate the angular value $t$ for every discrete grinding wheel surface point such that $z_{t}=0$. Thereby the position of each point crossing the workpiece plane at $z=0$ can be evaluated and at the same time, the exact value of the control variable $t$ can be allocated to each particular point. 


$$
\left[\begin{array}{cccc}
\cos t & -\sin t & 0 & 0 \\
\sin t & \cos t & 0 & 0 \\
0 & 0 & 1 & f_{0}+(t \cdot h) /(2 \pi) \\
0 & 0 & 0 & 1
\end{array}\right] \cdot\left[\begin{array}{c}
\mathrm{x}_{0}^{\mathrm{i}} \\
\mathrm{y}_{0}^{\mathrm{i}} \\
\mathrm{z}_{0}^{\mathrm{i}} \\
1
\end{array}\right]=\left[\begin{array}{c}
\mathrm{x}_{\mathrm{t}}^{\mathrm{i}} \\
\mathrm{y}_{\mathrm{t}}^{\mathrm{i}} \\
\mathrm{z}_{\mathrm{t}}^{\mathrm{i}} \\
1
\end{array}\right]
$$

where: $h$ - helix angle, $t$ - angular coordinate.

To determine the groove cross-section line, a geometric algorithm developed by Li et al. [17] is applied to the set of points lying inside the workpiece radius. Afterwards, the groove profile can be evaluated by means of the defining geometrical parameters: flute depth $t_{n}$, groove width $\varphi_{n}$ and rake angle $\gamma$.

\section{ACTIVE GRINDING WHEEL SURFACE AND THE PREVAILING CONTACT CONDITIONS}

In order to determine the active grinding wheel surface, an algorithm was developed that sorts out the transformed points that penetrate the $x-y$-plane for $z_{t}=0$ inside the workpiece's radius but in an area where another point has already passed before. Depending on the grinding wheel starting position, points with either a smaller or bigger allocated parameter $t$ surpass the workpiece plane at different times. In the example shown in Fig. 3, points with a larger value for $t$ are penetrating the workpiece cross-section earlier, which means that points with a smaller $t$ located in the same area as those with a larger value for $t$ can be deleted since they are not in contact during the real grinding process. As illustrated by the difference between Fig. $3 a$ and $3 b$ the number of actually active grinding wheel points is reduced by more than $50 \%$ in comparison to the size of the full point set.

a)

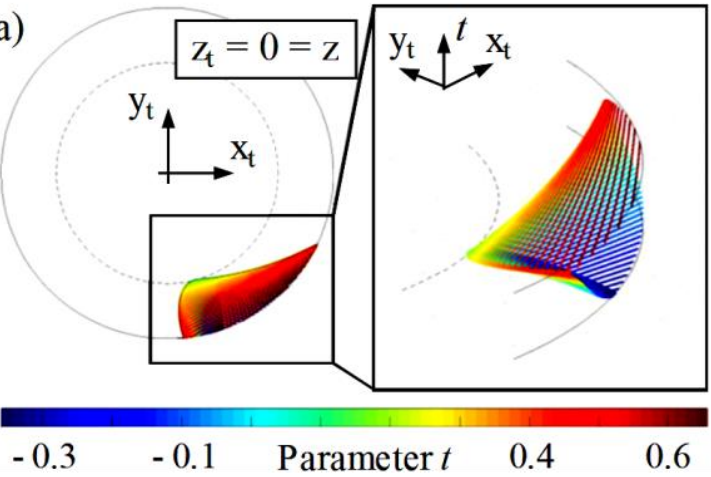

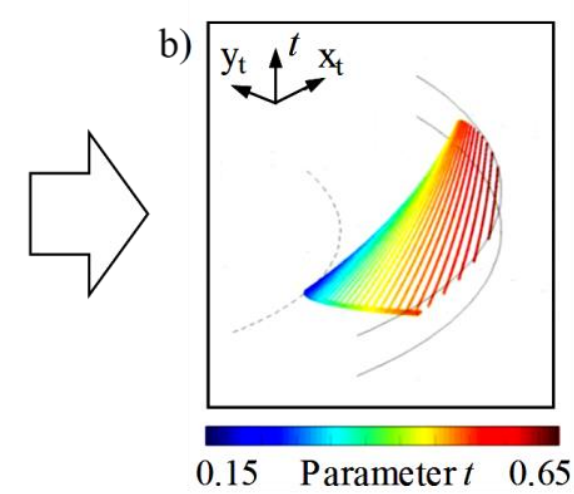

Fig. 3. Graphical representation of filter algorithm to determine active grinding wheel surface: a) all relevant transformed grinding wheel points plotted against control parameter $t, \mathrm{~b}$ ) active grinding wheel points filtered based on the value of parameter $t$

Now that the set of active grinding wheel points is known in the $\left\{x_{t}, y_{t}, z_{t}\right\}$ coordinate system, the coordinate transformations can be executed backwards so that the points actually manufacturing the groove profile can be projected onto the grinding wheel surface. Thereby, 
the active grinding wheel surface is described in the global coordinate system $\{x, y, z\}$ as indicated in Fig. 4a. In the next step, the workpiece surface is discretized as a cylinder where its position is transformed analogously to the grinding wheel's starting position (Fig. 4a). Following, the contact conditions can be analysed geometrically in the z-direction along the active grinding wheel width $b_{\text {act }}$, as shown exemplarily in Fig. $4 \mathrm{~b}$ for one intersecting plane, the geometrical contact length $l_{g}(z)$, as well as the maximum depth of cut $a_{e \cdot \max }(z)$, can be determined directly.

a)

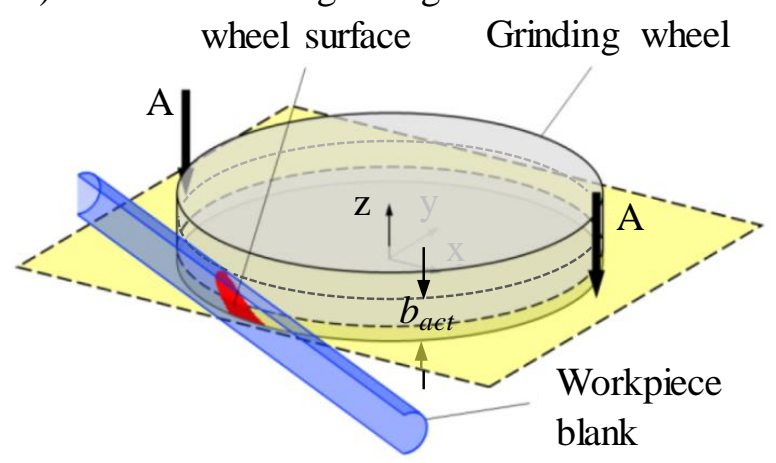

b)

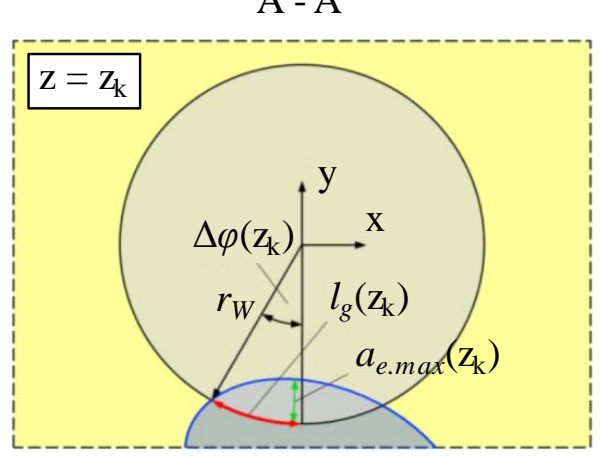

Fig. 4. Illustration of the geometric evaluation of the contact conditions: a) relative position of grinding wheel and workpiece blank, b) example of relevant values assessing the contact conditions

In order to analyse which parts of the grinding wheel are involved in the manufacturing of the flute, the grinding wheel surface was divided into three different areas according to the description of the grinding wheel contour (Fig. 1). As illustrated in Fig. 5, the share of grinding wheel areas involved in material removal and the groove contour processing differ substantially.

a)

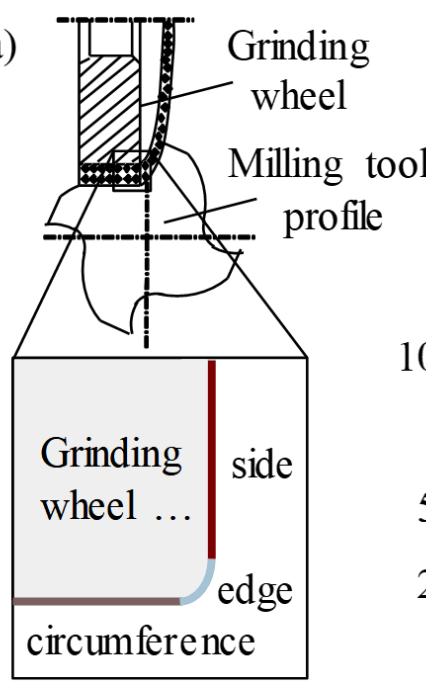

b) Groove profile

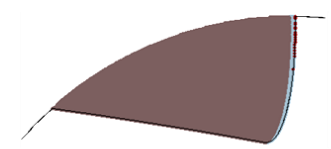

Share of areas involved in material removal

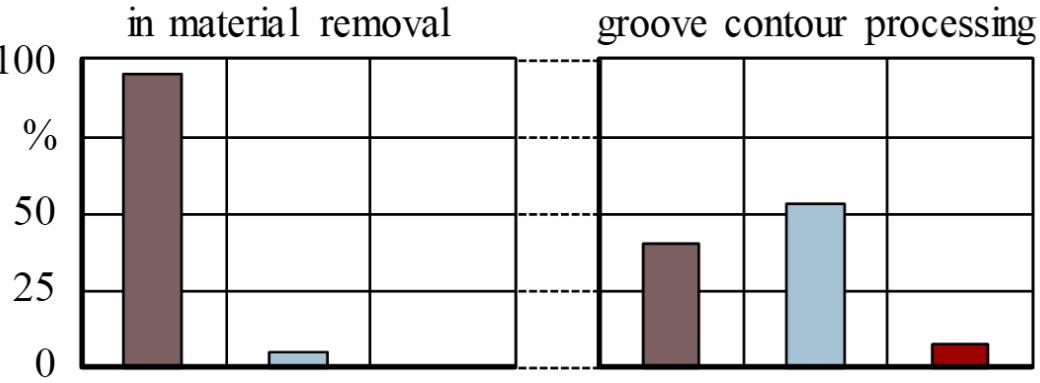

Fig. 5. Exemplary representation of the involvement of the different parts of the grinding wheel: a) illustration of different grinding wheel parts, b) share on material removal; c) share on groove contour processing 


\section{SIMULATION RESULTS AND THE DEDUCED TOOL CONCEPT}

The conducted simulations have shown that the kinematic parameters helix angle $\lambda$ and lead angle $\lambda_{V}$ have the biggest influence on the share of areas that are involved in material removal and groove contour processing. As presented in Fig 6, the grinding wheel side area is not involved in material removal for a lead angle of $\lambda_{V}>0.5^{\circ}$. Instead, the grinding wheel edge generates the rake face as well as the cutting edge of the circumference cutter and thus exposed to high loads. In contrast, the flute base is mainly processed by the grinding wheel circumference. The varying contact conditions affect the resulting surface quality. Especially at high cutting volumes, a constant work result can no longer be guaranteed due to the grinding wheel wear.

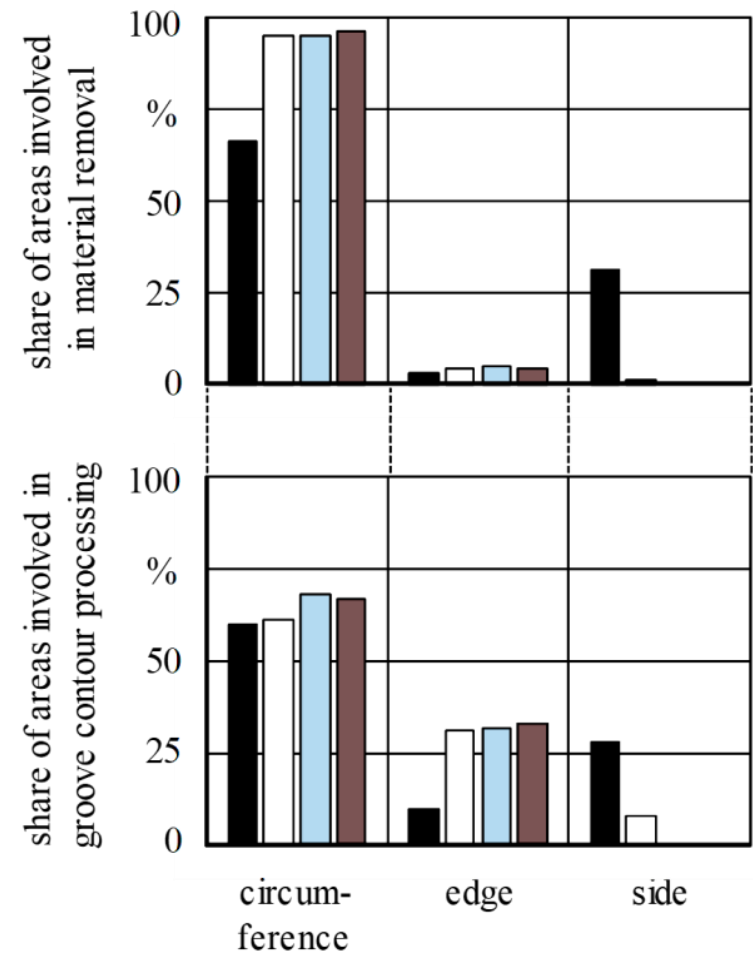

$\square \lambda_{V}=0.0^{\circ} \square \lambda_{V}=1.0^{\circ}$
$\square \lambda_{V}=0.5^{\circ} \square \lambda_{V}=2.0^{\circ}$

Grinding wheel geometry:

Wheel shape 1A1

$d_{S}=100 \mathrm{~mm}$

$b_{S}=10 \mathrm{~mm}$

$r_{\beta S}=0.1 \mathrm{~mm}$

Groove geometry:

$d_{W}=12 \mathrm{~mm}$

$t_{N}=2 \mathrm{~mm}$

$\lambda=0$ ०

$\gamma=0 \quad 0$

Simulation parameter:

Resolution $a_{\text {res }}=10 \quad \mu \mathrm{m}$

Fig. 6. Simulative investigation of the lead angle's influence on the share of the different grinding wheel areas' involvement in material removal and groove contour processing

Based on those findings, layered grinding wheels were designed and the application behaviour was analysed with respect to the complex contact conditions. To increase the wear resistance, a high grain concentration was set in the edge region (Fig. 7a). In order to analyse the process behaviour, simulations were carried out with a non-layered grinding wheel and a layered grinding wheel with two different abrasive specifications varying over the grinding wheel width. The geometric contact length $l_{g}$ and the maximum depth of cut $a_{e \text { max }}$ can be directly determined over the grinding wheel width $b_{S}$, which is not dependent on the abrasive specification. The results are presented in Fig. $7 \mathrm{~b}$. 
a)
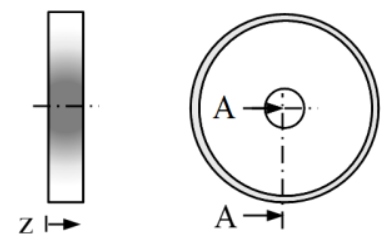

Sectional view A-A (enlarged) Sectional view A-A (enlarged) non-layered grinding wheel layered grinding wheel

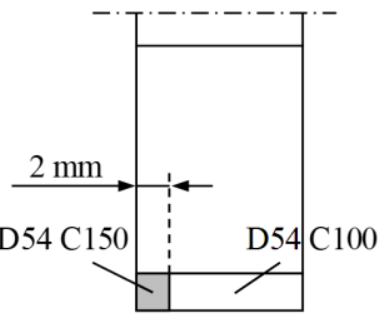

b) - geometric contact length $l_{g}$

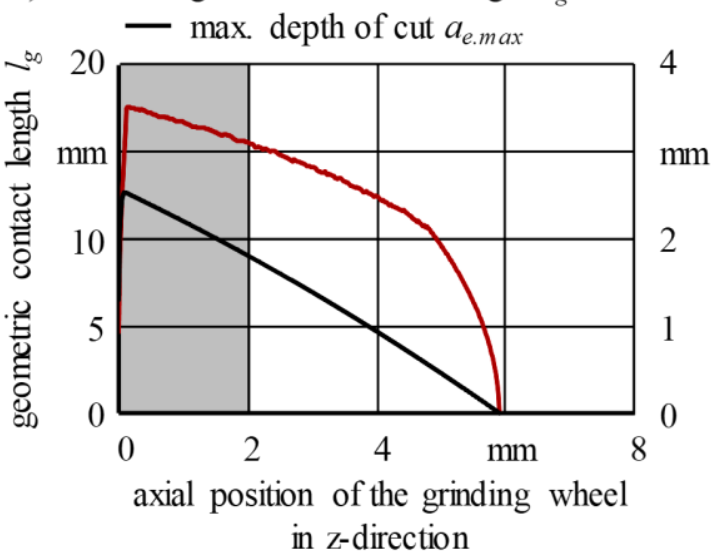

Groove geometry:

$d_{w}=12 \mathrm{~mm}$

$t_{N}=3 \mathrm{~mm}$

$\lambda=0$ 。

$\lambda_{v}=2.5^{\circ}$

$\gamma=0$ 。

Grinding wheel geometry:

Wheel shape $1 \mathrm{Al}$

‡ $d_{s}=100 \mathrm{~mm}$

$b_{s}=10 \mathrm{~mm}$

$r_{\beta s}=0.1 \mathrm{~mm}$

in z-direction

Fig. 7. Layered grinding wheel specifications and simulated contact conditions, a) illustration of the grinding wheel,

b) results of the simulation considering geometric contact length $l_{\mathrm{g}}$ and max. depth of cut $a_{e \text {.max }}$

Other grinding specific parameters such as the material removal rate $Q^{\prime}{ }_{w}$ and the maximum chip thickness $h_{c u \text { max }}$ can be derived directly from the maximum depth of cut $a_{e \text {.max. }}$. The material removal rate $Q^{\prime}{ }_{w}(z)$ can be calculated according to equation 2 , with a given feed rate $v_{f}$.

$$
Q_{w}^{\prime}(z)=a_{e \cdot \max } \cdot v_{f}
$$

where: $Q_{w}^{\prime}-$ material removal rate, $a_{e \cdot \max }-$ maximum depth of cut, $v_{f}-$ feed rate.

To calculate the maximum chip thickness $h_{\text {cu.max }}$, the kinematic process parameters and the grinding wheel topography characteristics $C_{1}$ and $\tan (\chi)$ are used as input variables, equation $3[18,19]$

$$
h_{\text {cu.max }}=0.695 \cdot\left(\frac{2}{C_{1} \tan (\chi)}\right)^{\frac{1}{3}} \cdot\left(\frac{v_{\mathrm{f}}}{v_{\mathrm{s}}}\right)^{\frac{1}{3}} \cdot\left(\frac{a_{\mathrm{e} . \max }}{d_{\mathrm{eq}}}\right)^{\frac{1}{6}}
$$

where: $C_{1}$ - grain concentration, $\chi$-average grain angle, $v_{f}$-feed rate, $v_{s}$-cutting speed, $a_{e \cdot \max }-$ maximum depth of cut, $d_{e q}-$ equivalent grinding wheel diameter

The grain concentration $C_{1}$ and the average grain angle $\chi$ are determined by another numerical tool that was developed to evaluate different grinding wheel topographies [7]. It identifies cutting edges depending on the nominal grain diameter (Fig. 8). After that, the angles of all detected cutting edges are evaluated to determine the average grain angle $\chi$. 


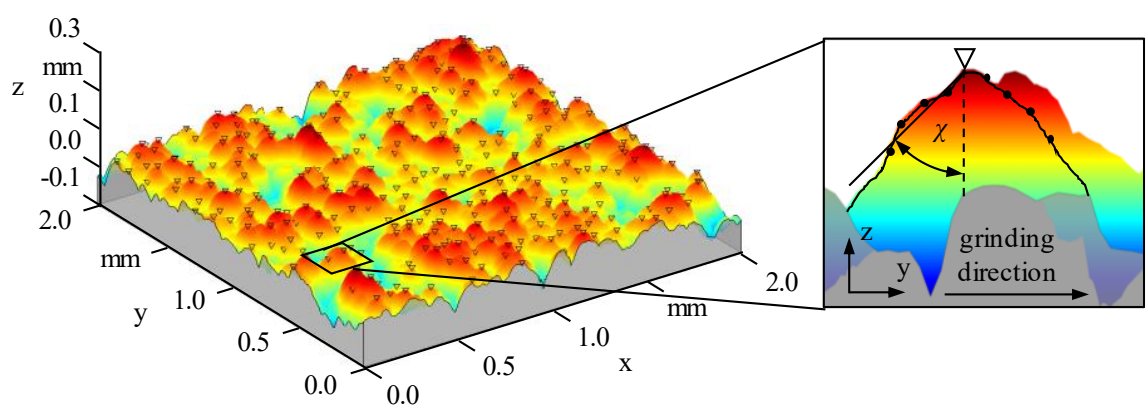

Fig. 8. Topography analysis including grain identification and cutting-edge evaluation

Topography measurements were carried out to determine the grinding wheel characteristics. A non-layered grinding wheel of type D54 C100 from Diamant-Gesellschaft TESCH GmbH, Ludwigsburg, Germany, with the characteristic values listed in Table 1 was used. The main grain concentration of the layered grinding wheel was also C100 but near the edge area, the grain concentration $\mathrm{C} 150$ was chosen. The volumetric grain proportion for a grinding wheel $\mathrm{C} 100$ is $25 \%$ and $\mathrm{C} 150$ is $37.50 \%$. It was assumed that a change of the volumetric grain proportion corresponds to a change of the grain concentration $C_{1}$ in the same ratio. Since the same grain size is considered over the grinding wheel width, no change in the value proportionality factor $\tan (\chi)$ is expected. The corresponding values for the edge area of the layered grinding wheel are also listed in Table 1.

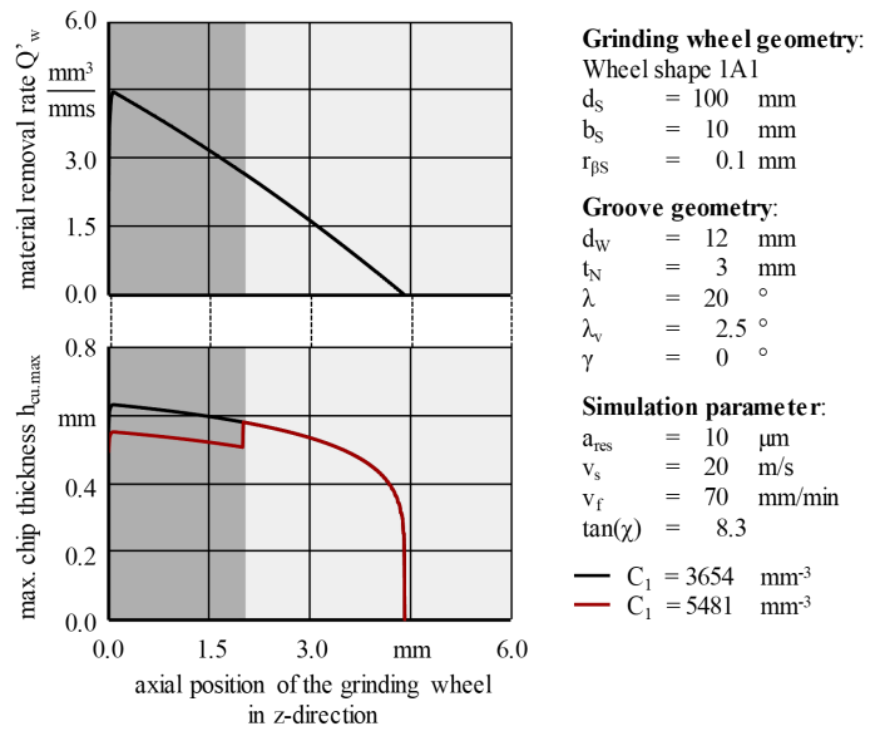

Fig. 9. Simulated material removal rate $Q^{\prime}{ }_{w}$ and max. chip thickness $h_{c u \text { max }}$ for layered and non-layered grinding wheel

Table 1. Specifications for grinding wheel layers

\begin{tabular}{|l|c|c|}
\hline Grinding wheel characteristics & D54 C100 & D54 C150 \\
\hline Grain concentration $C_{1}$ & $3654 \mathrm{~mm}^{-3}$ & $5481 \mathrm{~mm}^{-3}$ \\
\hline Proportionality factor $\tan (\chi)$ & 8.3 & 8.3 \\
\hline
\end{tabular}


In order to analyse the application, simulations were performed with a helix angle $\lambda=20^{\circ}$, a lead angle $\lambda_{v}=2.5^{\circ}$, a circumferential speed $v_{s}=20 \mathrm{~m} / \mathrm{s}$ and a feed rate of $v_{f}=70 \mathrm{~mm} / \mathrm{min}$. Figure 9 shows the results for the non-layered and the layered grinding wheel. The course of the material removal rate $Q^{\prime}{ }_{w}(z)$ over the grinding wheel width is equal for the investigated grinding wheels since the topography characteristics are not included in the calculation. The influence of the layered grinding wheel topography can be seen in the course of the maximum chip thickness $h_{\text {cumax. }}$. An increase in the grain concentration reduces the maximum chip thickness $h_{c u \text { max }}$, which at the same time results in a lower singlegrain load near the edge region of the grinding wheel. It can be assumed that the reduction of the load has a positive effect on the wear behaviour and thus improves the process behaviour of the grinding wheels.

\section{CONCLUSION}

With the developed geometrical-kinematic simulation tool it is possible to analyse the complex contact conditions between workpiece blank and grinding wheel during grinding of helical flutes by determining the active grinding wheel surface. Furthermore, grinding relevant parameters can be evaluated over the active grinding wheel width $b_{\text {act. }}$ It could be identified that the flute contour is machined by different areas of the active grinding wheel depending especially on the kinematic parameters helix angle $\lambda$ and lead angle $\lambda_{v}$. Based on the simulative process analysis, application-oriented layered grinding wheels were designed to take the complex contact conditions of the process into account. Therefore, the grain concentration was increased in the edge region which is responsible for the generation of the rake face and the cutting edge. The results of the simulative study of layered grinding wheels show their potential to increase the wear resistance by reducing the maximum chip thickness $h_{c u \text {.max }}$ in edge area. Due to the increased wear resistance, the microgeometry and the edge rounding of the grinding wheels can be kept constant over a higher material removal rate, resulting in economical and qualitative improvements during flute grinding. Following the findings of this study, experimental investigations are planned to analyse the functionality of layered grinding wheels and the process behaviour of the produced milling tools.

\section{REFERENCES}

[1] BEJU L.D., BRINDASU D.P., MUTIU N.C., ROTHMUND J., 2016, Modeling, Simulation and Manufacturing of Drill Flutes, International Journal of Advanced Manufacturing Technology, 83/9, 2111-2127.

[2] CHIANG C.J., FONG Z.H., TSENG J.T., 2009, Computerized Simulation of Thread from Grinding Process, Mechanism and Machine Theory, 44/4, 685-696.

[3] DENKENA B., TRACHT K., DEICHMÜLLER M., 2006, Wechselwirkungen zwischen Struktur und Prozess beim Werkzeugschleifen, wt Werkstattstechnik online, 11/12, 814-819.

[4] DENKENA B., HOLLMANN F., 2013, Process Machine Interactions - Prediction and Manipulation of Interactions between Manufacturing Processes and Machine Tool Structures, Berlin, Heidelberg, Springer.

[5] EHMANN K.F., DE VRIES M.F., 1990, Grinding Wheel Profile Definition for the Manufacture of Drill Flutes, CIRP Annals - Manufacturing Technology, 39/1, 153-156. 
[6] FRIEDMANN M.Y., BOLSELAVSKI M., MEISTER I., 1972, The Profile of a Helical Slot Machined by a DiskType Cutter with an Infinitesimal Width, Considering Undercut-Ting, Proceedings of the 13th International Machine Tool Design Research Conference, 245-246.

[7] HSIEH J., 2006, Mathematical Model and Sensitivity Analysis for Helical Groove Machining, International Journal of Machine Tools and Manufacture, 46/10, 1087-1096.

[8] HÜBERT C., 2012, Schleifen von Hartmetall- und Vollkeramik-Schaftfräsern, Berichte aus dem Produktionstechnischen Zentrum Berlin, Berlin, Fraunhofer Verlag.

[9] KALDOR S., RAFAEL A.M., MESSINGER D., 1988, On the CAD of Profiles for Cutters and Helical Flutes Geometrical Aspects, CIRP Annals - Manufacturing Technology, 37/1, 53-56.

[10] KANG S.K., EHMANN K.F., LIN C., 1996, A CAD Approach to Helical Groove Machining - I. Mathematical Model and Model Solution, International Journal of Machine Tools and Manufacture, 36/1, 141-153.

[11] KASSEN G., 1969, Beschreibung der elementaren Kinematik des Schleifvorgangs, Rheinisch-Westfälische Technische Hochschule, Aachen, Diss.

[12] KIM J.H., PARK J.W., KO T.J., 2008, End Mill Design and Machining via Cutting Simulation, Computer-Aided Design, 40/3, 324-333.

[13] LI G., SUN J., LI J., 2014, Modeling and Analysis of Helical Groove Grinding in End Mill Machining, Journal of Materials Processing Technology, 214/12, 3067-3078.

[14] MOHAN L.V., SHUNMUGAM M.S., 2004, CAD Approach for Simulation of Generation Machining and Identification of Contact Lines, International Journal of Machine Tools \& Manufacture, 44, 717-723.

[15] SHETH E., MALKIN S., 1990, CAD/CAM for Geometry and Process Analysis of Helical Groove Machining, CIRP Annals - Manufacturing Technology, 39/1, 129-132.

[16] SUN Y., WANG J., GUO D., ZHANG Q., 2006. Modeling and Numerical Simulation for the Machining of Helical Surface Profiles on Cutting Tools, The International Journal of Advanced Manufacturing Technology, 36, 525-534.

[17] UHLMANN E., HÜBERT C., 2011, Tool Grinding of End Mill Cutting Tools Made from High Performance Ceramics and Cemented Carbides, CIRP Annals, 60, 359-362.

[18] WANG L., CHEN Z.C., LI J., SUN J., 2016, A Novel Approach to Determination of Wheel Position and Orientation for Five-Axis CNC Flute Grinding of End Mills, International Journal of Advanced Manufacturing Technology, 84/9, 2499-2514.

[19] WERNER G., 1971, Kinematik und Mechanik des Schleifprozesses, Rheinisch-Westfälische Technische Hochschule Aachen, Diss. 